\title{
Sports injury and illness incidence in the PyeongChang 2018 Olympic Winter Games: a prospective study of 2914 athletes from 92 countries
}

\author{
Torbjørn Soligard, ${ }^{\odot 1,2}$ Debbie Palmer, ${ }^{3,4}$ Kathrin Steffen, ${ }^{\oplus 5}$ Alexandre Dias Lopes, ${ }^{\odot} 6$ \\ Marie-Elaine Grant ${ }^{7}$ DooSup Kim, ${ }^{8,9}$ Sae Yong Lee, ${ }^{8,10}$ Natalia Salmina, ${ }^{11}$ \\ Brett G Toresdahl, ${ }^{12}$ Joon Young Chang, ${ }^{8}$ Richard Budgett, ${ }^{1}$ Lars Engebretsen ${ }^{1,5}$
}

\begin{abstract}
- Additional material is published online only. To view please visit the journal online (http://dx.doi.org/10.1136/ bjsports-2018-100236).
\end{abstract}

For numbered affiliations see end of article.

\section{Correspondence to} Dr Torbjørn Soligard, Medical and Scientific Department, International Olympic Committee, Lausanne, Switzerland; torbjorn.soligard@olympic.org

Accepted 5 June 2019 Published Online First 23 June 2019

\section{Check for updates}

(C) Author(s) (or their employer(s)) 2019. No commercial re-use. See rights and permissions. Published by BMJ.

\footnotetext{
To cite: Soligard T,

Palmer D, Steffen K,

et al. Br J Sports Med

2019:53:1085-1092.
}

\begin{abstract}
Objective To describe the incidence of injuries and illnesses sustained during the XXIII Olympic Winter Games, hosted by PyeongChang on 9-25 February 2018.

Methods We recorded the daily number of athlete injuries and illnesses (1) through the reporting of all National Olympic Committee (NOC) medical teams and (2) in the polyclinic and medical venues by the PyeongChang 2018 medical staff.
\end{abstract}

Results In total, 2914 athletes (1210 women, 42\%; 1704 men, 58\%) from 92 NOCs were observed for occurrence of injury and illness. NOC and PyeongChang 2018 medical staff reported 376 injuries and 279 illnesses, equalling 12.6 injuries and 9.4 illnesses per 100 athletes over the 17-day period. Altogether, 12\% of the athletes incurred at least one injury and $9 \%$ at least one illness. The injury incidence was highest in ski halfpipe (28\%), snowboard cross (26\%), ski cross (25\%), snowboard slopestyle (21\%) and aerials (20\%), and lowest in Nordic combined, biathlon, snowboard slalom, moguls and cross-country skiing (2\%-6\%). of the 376 injuries recorded, $33 \%$ and $13 \%$ were estimated to lead to $\geq 1$ day and $>7$ days of absence from sport, respectively. The highest incidences of illness were recorded in biathlon (15\%), curling (14\%), bobsleigh (14\%) and snowboard slalom (13\%). Thirty per cent of the illnesses were expected to result in time loss, and $70 \%$ affected the respiratory system. Women suffered $61 \%$ more illnesses than men.

Conclusion Overall, $12 \%$ of the athletes incurred at least one injury during the Games and 9\% an illness, incidences that are similar to the Olympic Winter Games of 2010 and 2014.

\section{INTRODUCTION}

It is well recognised that routine physical activity elicits a number of health benefits, including a reduction in the risk of numerous chronic diseases and premature death. ${ }^{12}$ Compared with the general population, elite athletes seem to gain additional health benefits in the form of greater life expectancy and lower risk of disease and hospital admission. ${ }^{3-7}$ However, concomitantly they run a higher risk of musculoskeletal disorders during and longterm disability after the end of their careers. ${ }^{4-11}$

Systematic injury and illness surveillance is a prerequisite to effective protection of the health of the athletes, by providing essential information on the extent and incidence of injuries and illnesses occurring in sports. These epidemiological data contribute to better planning and provision of athlete healthcare, and importantly objectively inform and help to advance the development of measures to prevent injury and illness. Guided by these data, future injury and illness risk factor and mechanism research can identify and influence factors linked to injury or illness risk, such as the safety precautions in sport rules and regulations, or the training programmes and equipment used by athletes. 1213

Several International Sports Federations and research institutes have set up injury and illness surveillance systems either longitudinally, over one or more seasons, or during certain main events. ${ }^{14-76}$ At the Beijing 2008 Olympic Games, the IOC commissioned the first major IOC injury surveillance system, ${ }^{77} 78$ which was subsequently expanded for Vancouver 2010 to also include illnesses. ${ }^{79}$ Since then, the surveillance system has been continued and further developed in London 2012, ${ }^{80}$ Sochi $2014^{81}$ and Rio $2016 .{ }^{82}$ In these Games, the injury and illness incidences ranged from 9.6 to 14.0 injuries and from 5.4 to 8.9 illnesses per 100 athletes.

Our aim was to describe the incidence and characteristics of the sports injuries and illnesses occurring during the PyeongChang 2018 Olympic Winter Games.

\section{METHODS}

We employed the IOC injury and illness surveillance system for multisport events in this prospective cohort study. ${ }^{77}$ We invited all National Olympic Committee (NOC) medical teams to report the daily occurrence (or non-occurrence) of athlete injuries and illnesses using an electronic report form (side module of General Electric Athlete Management Solution; GE AMS). Concurrently, we retrieved the same information on all athletes treated for injuries and illnesses in the polyclinic and all other medical venues operated by the Organizing Committee of the Olympic and Paralympic Games PyeongChang 2018 medical staff. These data were collected through an electronic medical record system (GE AMS).

\section{Implementation}

Three months in advance we informed the NOCs about the study by letter. The day before the opening of the Games, we organised a meeting for all NOC medical staff. At this meeting we 
informed them about the protocol, answered questions, created user accounts for the GE AMS injury and illness reporting system, and distributed tablet computers to facilitate their daily reporting.

Throughout the data collection, we actively followed up NOCs comprising 10 or more participating athletes with frequent visits to address any questions and encourage continuous reporting during the games. We recorded the response rate of all the 92 participating NOCs. At the end of the Games, NOC medical staff with a response rate of $100 \%$ could keep their tablet computer.

\section{Definition of injury and illness}

We defined injuries and illnesses as new (pre-existing, not fully rehabilitated conditions were not recorded) or recurring (athletes having returned to full participation after a previous condition) incurred in competition or training during the PyeongChang Olympic Games (9-25 February 2018) receiving medical attention, regardless of the consequences with respect to absence from competition or training. ${ }^{77}$ Injuries included musculoskeletal complaints, concussions and other non-musculoskeletal trauma. In cases where a single incident caused multiple injury types, we recorded only the most severe diagnosis-as determined by our research team based on all available clinical data-for analysis. Severe injuries and illnesses were defined as injuries or illnesses estimated to lead to absence from training or competition of more than 1 week.

\section{Injury and illness report form}

Our injury and illness report form followed the template of that used in the Vancouver 2010, London 2012, Sochi 2014 and Rio 2016 Olympic Games. ${ }^{79-82}$ With respect to injuries, we recorded the following data: accreditation number, name, sport and event, whether the injury occurred in competition or training, date and time, body part, type, cause, and estimated time lost from competition or training. We recorded data on illnesses in a similar fashion: accreditation number, sport and event, date, affected system, main symptom(s), cause, and estimated time loss.

We provided instructions and examples on how to complete the form correctly. Furthermore, the report form was available in nine languages: English, French, Arabic, Chinese, German, Japanese, Korean, Russian and Spanish.
Confidentiality

In addition to the aforementioned variables, we queried the IOC athlete database for the age, sex, and nationality of the injured or ill athlete. We treated all information confidentially, and de-identified our database after the Games, ensuring anonymity of all athletes.

\section{Patient and public involvement}

Patients were not involved in planning the research priorities, research questions, outcome measures, study design or conduct. We will invite patients and the public to help with dissemination and evaluation of the study and the results.

\section{Data analysis}

In cases where athletes were treated for the same condition by both the NOC and PyeongChang 2018 medical staff, we retained the most complete data source.

We calculated the summary measures of injury and illness incidences $(i)$ according to the formula $i=n / e$, where $n$ is the number of injuries or illnesses in competition, training or in total during the study period, and $e$ the respective number of exposed (participating) athletes, with incidence proportions presented as injuries/illnesses per 100 athletes. We also calculated the summary measures of injury and illnesses per 1000 athlete-days, where athlete-days correspond to the total number of athletes multiplied by 17 days. We calculated confidence intervals (CI) of the risk ratio (RR) of the number of injuries or illnesses between the two groups by a Poisson model, assuming constant hazard per group and adjusting for sport, sex and/or NOC size (by the number of athletes) where appropriate. We present injury and illness incidences as means and RRs with 95\% CIs. We regarded two-tailed $\mathrm{p}$ values $<0.05$ as significant.

\section{RESULTS}

In total, 2914 athletes took part in the PyeongChang Olympic Games. Of these, 1210 were women (42\%) and 1704 men (58\%). There were 67 double-starters, meaning athletes who participated in two different sports or disciplines, giving a total of 2981 athlete exposures to injury or illness.

Throughout the 17 days of the Games, NOCs submitted 1242 of a maximum of 1564 daily reports $(79 \% ; 15$ countries did not submit any data) (table 1). The response rate of the 36 NOCs

\begin{tabular}{|c|c|c|c|c|c|}
\hline & $<10$ & $10-49$ & $50-99$ & $>99$ & All \\
\hline Number of NOCs (athletes) & $56(159)$ & $16(391)$ & $7(472)$ & $13(1892)$ & $92(2914)$ \\
\hline Injuries (per 100 athletes) & $29(18.2)$ & $58(14.8)$ & $34(7.2)$ & $255(13.5)$ & $376(12.9)$ \\
\hline Illnesses (per 100 athletes) & $26(16.4)$ & $39(10.0)$ & $48(10.2)$ & $166(8.8)$ & 279 (9.6) \\
\hline Daily reports submitted (\%) & $644(67.6)$ & $266(97.8)$ & $114(95.8)$ & $218(98.6)$ & $1242(79.4)$ \\
\hline \multicolumn{6}{|c|}{ Recorded by both NOC and OCOG } \\
\hline Injuries (\%) & $7(24.1)$ & $17(29.3)$ & $9(26.5)$ & $68(26.7)$ & $101(26.9)$ \\
\hline Illnesses (\%) & $6(23.1)$ & $7(17.9)$ & $2(4.2)$ & $2(1.2)$ & $17(6.1)$ \\
\hline \multicolumn{6}{|l|}{ Recorded only by NOCs } \\
\hline Injuries (\%) & $8(27.6)$ & $24(41.4)$ & $18(52.3)$ & $135(52.3)$ & $185(49.2)$ \\
\hline Illnesses (\%) & $5(19.2)$ & $23(59.0)$ & $45(93.8)$ & $120(72.3)$ & $193(69.2)$ \\
\hline \multicolumn{6}{|l|}{ Recorded only by OCOG } \\
\hline Injuries (\%) & $14(48.3)$ & $17(29.3)$ & $7(20.6)$ & $52(20.4)$ & $90(23.9)$ \\
\hline Illnesses (\%) & $15(57.7)$ & $9(23.1)$ & $1(2.1)$ & $44(26.5)$ & $69(24.7)$ \\
\hline
\end{tabular}




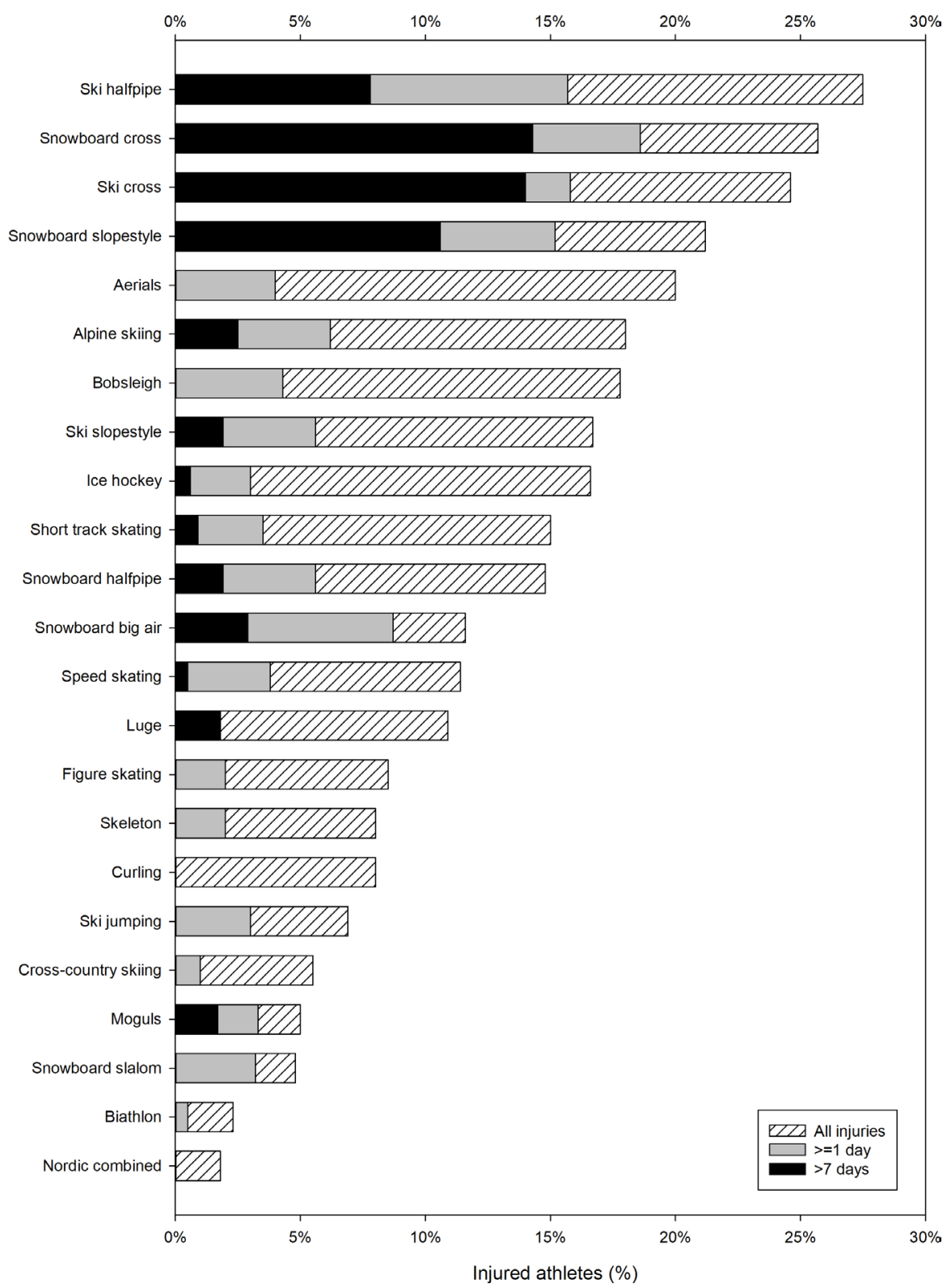

Figure 1 Proportions of athletes (\%) in each sport with injury, injury with estimated time loss $\geq 1$ day and injury with estimated time loss $>7$ days.

with $\geq 10$ participating athletes (accounting for $95 \%$ of all the athletes) was $98 \%$ (598 of 612 reports).

\section{Injuries overall, by sport and sex}

We recorded a total of 376 injuries, equalling 12.6 injuries (95\% CI 11.3 to 13.9$)$ per 100 exposed athletes. This corresponds to 7.4 injuries per 1000 athlete-days. On average, $12 \%(n=351)$ of the athletes sustained at least one injury. In addition, there were 25 athletes with two injuries each.

Figure 1 shows the incidence proportion of injured athletes in each sport (additional details are available in online supplementary appendix 1). The incidence of injury was highest in ski halfpipe (27.5 injuries (95\% CI 13.1 to 41.8 ) per 100 athletes), snowboard cross (25.7 (95\% CI 13.8 to 37.6$)$ ), ski cross (24.6 (95\% CI 11.7 to 37.4)), snowboard slopestyle (21.2 (95\% CI 10.1 to 32.3$)$ ) and aerials (20.0 (95\% CI 7.6 to 32.4$)$ ), and lowest in Nordic combined, biathlon, snowboard slalom, moguls and cross-country skiing (ranging from 2 to 6 injuries per 100 athletes).
When adjusting for sport and NOC size, there was no difference in overall injury incidence between women (13.7 injuries (95\% CI 11.6 to 15.7$)$ per 100 athletes) and men (11.9 (95\% CI 10.3 to 13.5$), \mathrm{RR}=1.15$ (95\% CI 0.94 to 1.41$)$; online supplementary appendix 2). However, female athletes were at significantly higher risk of injury in luge $(\mathrm{RR}=5.33$ (95\% CI 1.61 to 17.71)) and ice hockey ( $R R=1.68$ (95\% CI 1.09 to 2.59$))$, while at lower risk in curling ( $\mathrm{RR}=0.13$ (95\% CI 0.02 to 0.99$)$ ) and speed skating $(\mathrm{RR}=0.29$ (95\% CI 0.10 to 0.87$)$ ).

Severity of injuries

While two-thirds of the injuries were estimated to result in no time loss from sport $(n=252,67 \%), 33 \%$ of the injuries $(n=124)$ were expected to prevent the athlete from participating in competition or training (online supplementary appendix 1). It was estimated that $15 \%$ of the injuries $(n=56)$ would result in an absence from sports from 1 to 3 days, $5 \%(n=19)$ in an absence from 4 to 7 days, $6 \%(n=21)$ in an absence from 8 to 28 days, and $7 \%(n=28)$ in an absence for more than 28 days. Figure 1 
Box 1 Information on the 49 severe injuries (estimated absence $>7$ days), with the sports with the highest numbers in brackets

- 17 fractures (4 in ski cross, 4 in snowboard cross, 2 in snowboard slopestyle, 2 in luge).

- 12 ligament ruptures/sprains (5 in alpine skiing, 4 in snowboard cross).

- 5 dislocations or subluxations (3 in snowboard slopestyle).

- 5 concussions ( 2 in ice hockey, 1 in ski halfpipe, 1 in ski cross, 1 in snowboard slopestyle).

- 3 bone contusions (1 in ski cross, 1 in snowboard big air, 1 in snowboard cross).

- 2 lesions of meniscus or cartilage (1 in alpine skiing, 1 in snowboard slopestyle).

- 2 tendon strains/ruptures (1 in speed skating, 1 in ski halfpipe).

- 1 spinal cord injury (ski cross)

- 1 impingement (ski halfpipe).

- 1 muscle contusions or haematoma (snowboard halfpipe).

shows the incidence of injuries estimated to lead to $\geq 1$ day and $>7$ days of absence in each sport, with snowboard and ski cross presenting the most injuries in both severity categories. Box 1 presents the details of the 49 injuries classified as 'severe'.

\section{Location and type of injuries}

The most commonly injured locations were the knee $(n=53)$, ankle $(n=34)$, hand/fingers $(n=29)$ and lower back $(n=27)$. The most common injury types were sprain/ligament rupture $(n=62)$, bone contusion $(n=57)$ and muscle contusion/haematoma $(n=50)$. The distributions of injury locations and injury types per sport are presented in online supplementary appendix 3 and 4 , respectively.

\section{Causes, mechanisms and onset of injury}

While $89 \%(n=333)$ of the injuries were reported to occur acutely, $10 \%(n=39)$ and $1 \%(n=2)$ were reported to be recurrent or chronic, respectively (information missing for two injuries). However, overuse was reported as the cause of $16 \%$ of injuries. The most commonly reported injury mechanisms were contact with a stagnant object (31\%) and non-contact acute injury. These mechanisms were particularly common in the sports presenting with the highest injury rates, such as ski halfpipe, snowboard slopestyle, and ski and snowboard cross (online supplementary appendix 5).

The time of injury onset showed that $46 \%$ of the injuries were sustained in competition and 48\% during training (information missing for 22 injuries; online supplementary appendix 1). The frequency of severe injuries (those estimated to result in greater than 7 days of absence) was greater in competition than in training $(\mathrm{RR}=2.50(95 \% \mathrm{CI} 1.35$ to 4.65$))$.

Injuries in training and competition differed significantly in characteristics (location, type, mechanism and subsequent time loss from sport) and in terms of incidence in different sports. Competition injuries were less common than training injuries in speed skating ( $\mathrm{RR}=0.20$ (95\% CI 0.06 to 0.69$)$ ), bobsleigh $(\mathrm{RR}=0.26(95 \% \mathrm{CI} 0.11$ to 0.64$))$, snowboard slalom (3 injuries in training vs 0 in competition) and biathlon (4 vs 0 injuries). Ice hockey was the only sport in which there were significantly more competition injuries compared with training injuries $(\mathrm{RR}=3.11$ (95\% CI 1.83 to 5.29$)$ ).
Illnesses overall, by sex, sport and severity

Among the 2981 exposed athletes, a total of 279 illnesses were reported, resulting in 9.4 illnesses (95\% CI 8.3 to 10.5) per 100 athletes. This corresponds to 5.5 illnesses per 1000 athlete-days. On average, $9 \%(\mathrm{n}=259)$ of the athletes incurred an illness, as there were 20 athletes with two illnesses each. When controlling for sport and NOC size, women (11.8 illnesses (95\% CI 9.9 to 13.7) per 100 athletes) were at significantly greater risk of experiencing an illness than men (7.6 (95\% CI 6.3 to 8.9), $\mathrm{RR}=1.61$ (95\% CI to 1.26 to 2.04 ); online supplementary appendix 6).

Figure 2 shows the incidence proportion of illness in each sport (additional details are available in online supplementary appendix 1). Biathlon was the sport with the highest illness incidence (15.1 illnesses (95\% CI 9.9 to 20.2) per 100 athletes), followed by curling (14.3 (95\% CI 7.3 to 21.3$)$ ), bobsleigh (14.1 (95\% CI 8.3 to 19.9$)$ ) and snowboard slalom (12.9 (95\% CI 4.0 to 21.8)). The lowest incidences of illness were seen in ski cross, moguls and ice hockey (ranging from 3 to 5 illnesses per 100 athletes).

One in three illnesses $(n=83,30 \%)$ were expected to result in absence from training or competition.

\section{Affected system, main symptoms and causes of illness}

A total of 194 illnesses (70\%) affected the respiratory system. The second, third and fourth most frequently affected systems were the digestive system $(n=36,13 \%)$, skin and subcutaneous tissue $(\mathrm{n}=15,5 \%)$ and the nervous system $(\mathrm{n}=11,4 \%)$, respectively. Infection was the most common cause of illness ( $n=176,63 \%$ of the illnesses). Of the 194 respiratory illnesses, 144 (74\%) were caused by an infection. The distributions of affected systems, main symptoms and causes of illness per sport are presented in online supplementary appendices $7-9$, respectively.

\section{Data sources, and injuries and illnesses per NOC size}

Only $27 \%$ of all injuries and $6 \%$ of all illnesses were captured by both the NOCs and the PyeongChang 2018 staff. While 49\% of the injuries and $69 \%$ of the illnesses were recorded solely by the NOCs, $24 \%$ and $25 \%$ of the injuries and illnesses, respectively, were recorded solely by the PyeongChang 2018 staff.

The majority of injured and ill athletes from the larger NOCs were seen internally by their own NOC medical staff, but by contrast athletes from smaller NOCs were to a greater extent relying on diagnosis and treatment from the PyeongChang 2018 medical staff (table 1).

When adjusting for sport and sex, there was also an inverse relationship between NOC size (measured in number of participating athletes) and the incidence of illness, with athletes from smaller NOCs suffering more illnesses (NOCs with $<10$ athletes: 16.4 (95\% CI 10.1 to 22.6) illnesses per 100 athletes vs NOCs with >99 athletes: 8.8 (95\% CI 7.4 to 10.1) illnesses per 100 athletes $(\mathrm{RR}=1.85$ (95\% CI 1.19 to 2.86$)$ ).

\section{DISCUSSION}

\section{Injuries in the Olympic sports}

The aim of the present paper was to describe and analyse the athlete injuries and illnesses which occurred during the PyeongChang 2018 Olympic Games. The incidence of injury in the PyeongChang Games (12\%) was slightly higher than those in Beijing $2008(10 \%),{ }^{78}$ Vancouver $2010(11 \%),{ }^{79}$ London 2012 $(11 \%)^{80}$ and Rio $\left.2016(8 \%)\right)^{82}$ and identical to that of Sochi 2014 $(12 \%) .{ }^{81}$ It was also lower than the injury incidences reported from the recent Paralympic Games. ${ }^{25}$ 27-29 3133 


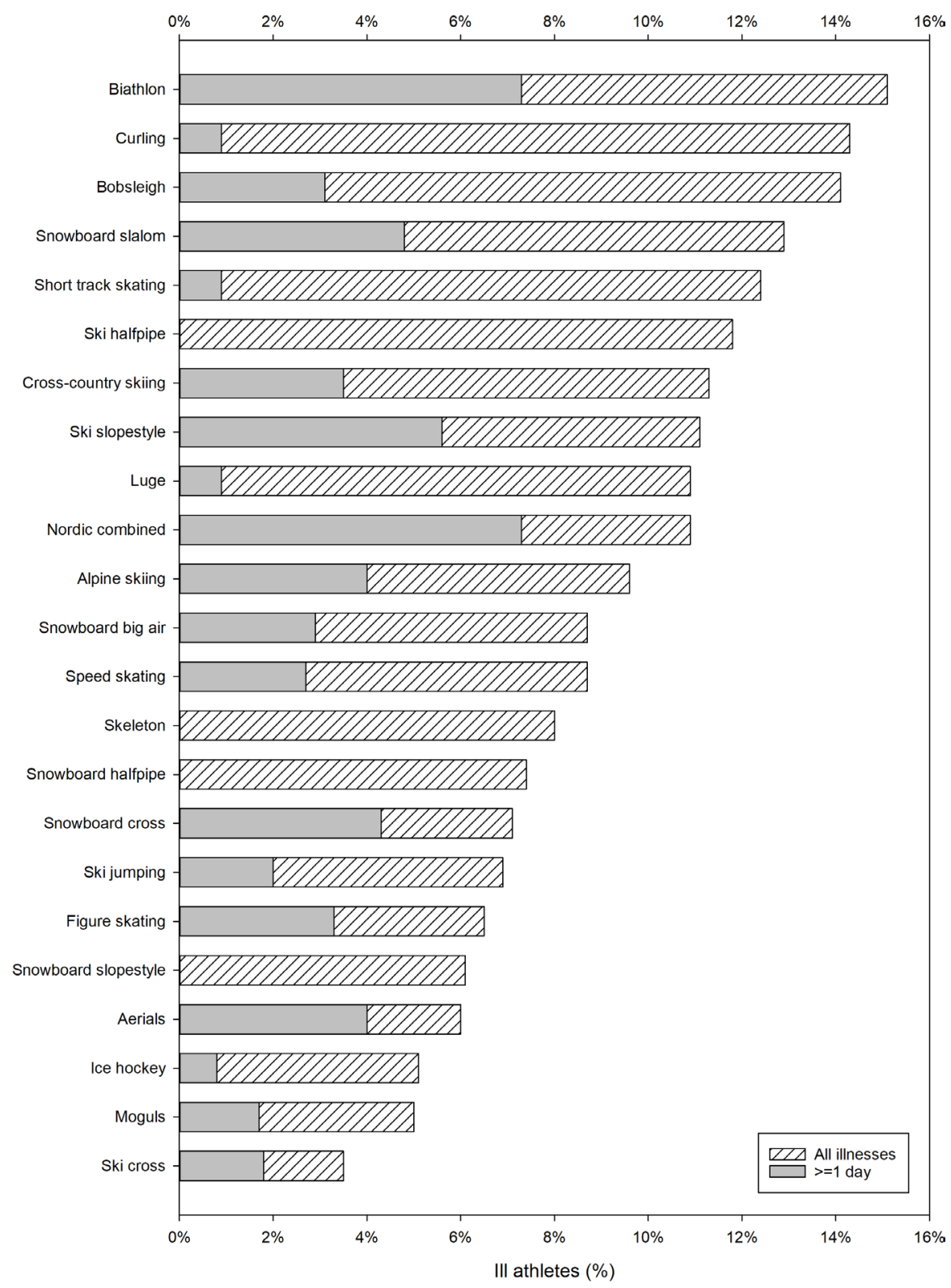

Figure 2 Proportions of athletes (\%) in each sport with illness and illness with estimated time loss $\geq 1$ day.

When comparing each sport in PyeongChang 2018 with Vancouver 2010, higher injury incidences were found in luge (11\% vs $2 \%$ of the athletes injured) and speed skating (11\% vs $3 \%)$. When doing a similar comparison with Sochi 2014, the injury incidences in PyeongChang were higher in ice hockey (17\% vs $11 \%)$ and speed skating ( $11 \%$ vs $5 \%$ ), but lower in biathlon (2\% vs $7 \%$ ), aerials (20\% vs $49 \%)$ and moguls (5\% vs $25 \%)$.

In general, our findings on the sports-specific injury rates in PyeongChang are corroborated by a large body of research from the Fédération Internationale de Ski (FIS) World Cup, where snowboard cross and halfpipe, ${ }^{445}$ aerial and halfpipe skiing and ski cross, ${ }^{4654}$ as well as particularly downhill of the alpine skiing events, ${ }^{45} 51$ have been identified as disciplines with higher rates of injury.

A change in injury incidence can be a consequence of changes in the composition of the Olympic Games programme, environmental factors, venue or track design, competition rules, or changes in equipment. In addition, in PyeongChang 2018, a new electronic medical record was used for the first time by both the
NOC and organising committee medical staff, which could potentially influence the sensitivity of the data collection. Also, incidence differences (lower or higher) may simply be the result of a natural variability of athletes' exposure to risk, an observation that emphasises the value of ongoing surveillance to monitor trends over time, for example, the effect of venue design, rule or equipment changes in the period between major sports events.

\section{Severity of injuries}

In major sports events, like the Olympic Games, injuries or illnesses of even minor severity with or without time loss have the potential to be both participation-limiting and performance-inhibiting, and thus prevent athletes from possibly fulfilling their potential and reaching their lifetime achievement. In the PyeongChang Games, 33\% of the injuries were estimated to result in time loss from competition or training of at least 1 day. This places PyeongChang 2018 between Sochi 2014 and Vancouver 2010 , in which the equivalent numbers were $39 \%$ and $23 \%$, 
respectively. In contrast, athletes in PyeongChang incurred fewer injuries of higher severity (13\% of the injuries estimated to result in an absence greater than 7 days) compared with athletes in Sochi 2014 and Vancouver 2010 (16\% and 17\%, respectively).

\section{Causes, mechanisms and onset of injury}

The causes, mechanisms and circumstances of injuries in competition and training differed significantly between the different sports. The vast majority of injuries in PyeongChang were reported to be acute, whereas overuse injuries accounted for just a tenth of the injuries. Although similar distributions were reported from both the summer and winter Olympic Games previously, these numbers should be interpreted with caution due to the limitations in the recording of overuse injuries in the current methodology. ${ }^{83-87}$

In ski halfpipe, snowboard slopestyle, and ski and snowboard cross, the most commonly reported injury mechanisms were contact with a stagnant object and non-contact acute injury. These aetiological data seem to confirm findings from previous studies showing that a preponderance of the injuries in these sports occur from falls and crashes related to jumps, kickers and the halfpipe, in other words in features that facilitate aerial manoeuvres. 50538889

With a fairly even distribution of injuries between training and competition ( $48 \%$ vs $46 \%$, respectively), the findings are similar to those from Vancouver 2010 (54\% vs 46\%), but differ from Sochi 2014 (63\% vs 35\%). As in Sochi 2014, ice hockey was the only sport in PyeongChang 2018 in which injuries occurred more commonly in competition than in training. These results correspond with earlier epidemiological findings. ${ }^{90-94}$ Ice hockey is a team and contact sport where the intensity, speed of play, number of body checks and fatigue are considerably higher in games-where more is at stake-than in training, where a significant amount of time is used for recovery and training drills of lower intensity.

\section{Illness risk during the Olympics}

The rate of illness in PyeongChang 2018 was similar to those reported in the Vancouver Games and Sochi Games $9 \%$ of all athletes affected in PyeongChang vs $8 \%$ Sochi and $7 \%$ in Vancouver). ${ }^{7981}$ Also consistent with the Vancouver and Sochi data is the difference in the illness incidence between female and male athletes, with women in PyeongChang experiencing 61\% more illnesses than men. The same disproportion has previously been reported in the Rio 2016 Paralympic Games, ${ }^{34}$ the 2009 athletics $^{35}$ and aquatics ${ }^{41}$ world championships, but not in the 2011 athletics $^{36}$ or 2013 aquatics ${ }^{42}$ world championships, the 1994-2009 US open tennis championships, ${ }^{95}$ or the London 2012 and Sochi 2014 Paralympic Games. ${ }^{30} 32$

The high incidence of respiratory infections mirrors data from other elite sport events. ${ }^{28} 303234-36415995-100$ While the primary causes are viruses such as the rhinovirus and parainfluenza virus, ${ }^{101} 102$ high-intensity and prolonged training and competition load is associated with an increased risk of both subclinical immunological changes (that may increase the risk of illness), and actual symptoms of illness or diagnosed illness. ${ }^{103-105}$ It is also known that frequent and prolonged international travelan inherent part of the elite athlete's life-can increase the risk of illness in athletes. ${ }^{97106}$

The Olympic Games are also subject to crowding of athletes, support staff and organising committee staff in the Olympic Village and venues. In addition, in PyeongChang, there were concerns about the hygiene in the Village and the workforce. These are factors that can influence the facility with which viruses and bacteria spread, and hence the incidence of infectious disease. Finally, a number of the cross-country skiing and biathlon events were held late in the evening, chiefly to accommodate projected peak viewership hours of international broadcasting. This may potentially have negatively influenced the frequency of respiratory illness, as the environmental and thermoregulatory conditions (cold temperatures and high wind speeds) often were exacerbated at these late hours.

When preparing for and going to events, athletes and their support staff should be aware that several effective behavioural, nutritional and training strategies exist to lower the exposure to pathogens and limit the extent of exercise-induced immunodepression, thereby mitigating the risk of illness. ${ }^{103}$ 107-109

\section{Methodological considerations}

In studies on sports injury, it is usually recommended to express incidences using a measure of time exposed to risk as the denominator. $^{28-30110111}$ However, considering the inherent complexity and size of the Olympic Games, this was not feasible in the present study. Instead, we expressed the injuries or illnesses by means of absolute risk: the number of new cases per 100 exposed athletes (incidence proportion). This approach erroneously assumes that the frequencies and lengths of exposure are identical in all sports and that the number of athletes at risk in each NOC is constant throughout the Games. Interpretation of differences in injury incidences or patterns should therefore be made with caution.

In the current study we defined injuries and illnesses as new or recurring injuries or illnesses receiving medical attention, regardless of the consequences with respect to absence from competition or training. By using such a definition, predominantly the moderate and severe acute injuries will be recorded. The less serious injuries may be overlooked, since such injuries do not always require medical attention, ${ }^{112} 113$ although our results show that the majority of reported injuries were not estimated to involve any absence from the sport. This finding may perhaps reflect that elite athletes have different coping mechanisms for pain to endure the demands of elite competition in which they continue to compete despite acute or overuse injury.

In the Olympic Games, all athletes have access to healthcare through the athletes' village polyclinic and the venue medical stations. However, the availability, size and quality of the NOCs' own medical teams vary between countries, meaning that not all athletes benefit from identical healthcare, which may bias the injury and illness recording.

In terms of the NOC response rate (of the countries with $\geq 10$ athletes), we received $98 \%$ of the expected daily reports. This is higher than in Rio 2016 (74\%), but similar to Sochi 2014 (99.7\%) and London 2012 (96\%). We believe the excellent response rate, as well as an observed improvement of data accuracy (less missing data), can partly be attributed to the implementation of a new electronic data collection system, which facilitated the daily data entry. In addition, as an incentive, we gifted a tablet computer at the end of the Games to NOCs with a 100\% response rate.

Twenty-seven per cent of the injuries and a mere 6\% of the illnesses were captured by both the NOC and the PyeongChang 2018 medical personnel, underlining the importance of both recorder groups. As it is possible that some cases were captured neither by the NOCs nor the PyeongChang medical staff, our results may potentially underestimate the true incidence of injuries or illnesses. Our study also shows that, in particular, athletes from smaller NOCs benefit from diagnosis and treatment from the local organising committee's medical staff, whereas the majority of athletes from larger NOCs are seen by their own NOC medical staff. More importantly, we once again identified an inverse relationship between NOC size and the risk of health problems, this 
time with athletes from the smallest NOCs experiencing significantly more illnesses compared with the largest NOCs. It is unknown whether this trend is related to differences in resources available to the NOCs, or to higher accuracy in the data recorded by PyeongChang 2018 staff (who to a larger degree treated athletes from smaller NOCs). In any event, the larger delegations usually come from countries with well-developed exercise physiology and sports medicine communities, and are generally able to offer their athletes more comprehensive healthcare and closer medical follow-up both in the lead up to and during the Games, potentially giving them a competitive advantage.

\section{Practical implications}

It is evident that there is a certain risk of injury inherent to any sports participation. While it would be entirely unrealistic to completely eradicate all injuries in sport, a very reasonable aim is to try to mitigate the risk-without changing the nature of the sport. Finding ways to mitigate health risks and protect the health of athletes, while still preserving the integrity of the sport, is the responsibility of all sports federations.

Based on epidemiological data collected in the Olympic Games and by FIS over the last 8 years, the IOC and FIS have initiated a set of studies looking into how and why injuries in the highrisk sports of snowboard and ski cross and slopestyle occur, with a long-term aim of developing injury prevention measures. The specific aim in these studies is to validate and develop tools to simulate jump construction as part of the course design. Such tools are only as valid as their input parameters, such as the take-off speed and angle, friction between ski/snowboard and the snow, air drag/lift, the range athletes can adjust the take-off direction by muscular work ('pop'), and use of the table shape/curvature. With this project, we hope to contribute to build a broader understanding of how the variability in these parameters can be monitored and controlled for in a validated model, and thus help to plan the design and construction of safe but attractive jumps in several disciplines. The aim is to mitigate landing impact and injury riskwhile still providing the athlete with the desired course characteristics and airtime. As different sports and disciplines change moving in the future, the epidemiological data collected by sports federations must be followed up by mechanism and risk factors studies, which in turn can inform injury and illness prevention initiatives.

What are the findings?

- Overall, $12 \%$ and $9 \%$ of the athletes incurred at least one injury or illness, respectively, during the PyeongChang 2018 Olympic Games.

- Ski halfpipe (28\%), snowboard cross (26\%), ski cross (25\%), snowboard slopestyle (21\%) and aerials (20\%) were the sports with the highest incidence of injury.

- Biathlon (15\%), curling (14\%), bobsleigh (14\%) and snowboard slalom (13\%) were the sports with the highest illness incidence.

\section{How might it impact on clinical practice in the future?}

- These injury and illness data can help inform policy and planning of major multisport events (eg, Olympic Games, Asian Winter Games, Winter X Games).

- These data must inform the focus and development of injury prevention measures in sport.
Such frameworks will allow athletes to perform at their highest level and take sports into the future, all the while keeping risks to their health to a minimum.

\section{CONCLUSION}

In summary, $12 \%$ of the athletes had a reported medical encounter for a new or recurrent injury and 9\% an illness during the PyeongChang Olympic Winter Games. The variations in incidence and characteristics of injuries and illnesses between sports and sexes indicate significantly different risk factors profiles, influenced by the characteristics and rules of the individual sport. Our results can inform both the planning and provision of healthcare to athletes in different sports, as well as further research on the aetiology of the injuries and illnesses which they incur.

\section{Author affiliations}

${ }^{1}$ Medical and Scientific Department, International Olympic Committee, Lausanne, Switzerland

${ }^{2}$ Sport Injury Prevention Research Centre, Faculty of Kinesiology, University of Calgary, Calgary, Alberta, Canada

${ }^{3}$ School of Applied Sciences, Edinburgh Napier University, Edinburgh, UK

${ }^{4}$ Division of Rheumatology, Orthopaedics and Dermatology, University of Nottingham School of Medicine, Nottingham, UK

${ }^{5}$ Department of Sports Medicine, Norwegian School of Sport Sciences, Oslo Sports Trauma Research Center, Oslo, Norway

${ }^{6}$ Department of Physical Therapy \& Kinesiology, University of Massachusetts Lowell, Lowell, Massachusetts, USA

${ }^{7}$ Institute of Sport and Health, University College Dublin, Dublin, Ireland

${ }^{8}$ Yonsei Institute of Sports Science and Exercise Medicine, Wonju, The Republic of

Korea

${ }^{9}$ Orthopaedic Surgery, Wonju College of Medicine, Yonsei University, Wonju, The Republic of Korea

${ }^{10}$ Department of Physical Education, Yonsei University, Seoul, The Republic of Korea ${ }^{11} \mathrm{GE}$ Healthcare, Moscow, Russian Federation

${ }^{12}$ Primary Care Sports Medicine Service, Department of Medicine, Hospital for Special Surgery, New York City, New York, USA

Acknowledgements We would like to acknowledge the contribution and support of the PyeongChang 2018 staff throughout the different stages of this study, particularly Chief Medical Officer, Prof Dr Young Hee Lee. We would also like to thank Dr Morten Fagerland at the Oslo Centre for Biostatistics and Epidemiology, Oslo University Hospital, for his important contributions to the statistical analyses. Finally, we would like to sincerely thank all the NOC medical staff contributing to the data collection: Dr Alban Merepeza (Albania), Dr Magdalena Kast (Argentina), Dr James McLaren (Australia), Dr Peter Braun (Australia), Dr Juergen Barthofer (Austria), Dr Anar Bagirov (Azerbaijan), Dr Henadz Zaharodny (Belarus), Dr Johan Bellemans (Belgium), Dr Said Fazlagic (Bosnia and Herzegovina), Dr Roberto Nahon (Brazil), Dr Parvran Parvanov (Bulgaria), Dr Robert McCormack (Canada), Dr Rodney French (Canada), Dr Suzanne Leclerc (Canada), Dr Lanne Peters (Canada), Dr David Manning (Canada), Dr Jeff Purkis (Canada), Dr Francis Fontaine (Canada), Dr Erika Persson (Canada), Dr Mireille Belzile (Canada), Dr Katie MacGregor (Canada), Dr Stephen French (Canada), Dr Mark Borzecki (Canada), Dr Jessica Curran (Canada), Dr Jose Rubio (Chile), Dr Carol Shuhua Dai (Chinese Taipei), Dr Judit Hernandez (Colombia), Dr Zoran Prso (Croatia), Dr Jakub Hermanek (Czech Republic), Dr Jiri Neumann (Czech Republic), Dr Vladimir Dobes (Czech Republic), Dr Kim Larsen (Denmark), Dr Pablo Sarmiento (Ecuador), Dr Mihkel Mardna (Estonia), Dr Maarit Valtonen (Finland), Dr Klaus Koehler (Finland), Dr Philippe Le Van (France, Andorra, Monaco), Dr Olivier Matarase (France), Dr Arthur Brule (France), Dr Mamuka Khabareli (Georgia), Dr Bernd Wolfarth (Germany), Dr Derick Macleod (Great Britain), Dr Stratos Karetos (Greece), Dr Erica Yu (Hong Kong), Dr Andras Tallay (Hungary), Dr Toth Szabolcs (Hungary), Dr Maria Magnusdottir (Iceland), Dr Bahram Savehshemshaki (Iran), Dr Sarah Jane McDonnell (Ireland), Dr Lubov Galitskaya (Israel), Dr Barbara Di Giancinto (Italy), Dr Claudio Gallozzi (Italy), Dr Jenny Birch (Jamaica), Dr Makoto Yoshida (Japan), Dr Toru Okuwaki (Japan), Dr Irina Myuller (Kazakhstan), Dr Jungjoong Yoon (Korea), Dr Liga Cirule (Latvia), Dr Raymond Succar (Lebanon), Dr Nebojsha Nastov (Macedonia), Dr Sasho Popovski (Macedonia), Dr Carlos Pruneda (Mexico), Dr Larisa Pipo (Moldova), Dr Bayartuya Bayarsaikhan (Mongolia), Dr Cees-Rein van den Hoogenband (The Netherlands), Dr Rutledge Ginny (New Zealand), Dr Rebecca Longhurst (New Zealand), Dr Effi Usen (Nigeria), Dr Mona Kjeldsberg (Norway), Dr Alexander Fomin (Olympic Athletes from Russia),

Dr Shahid Nadeem (Pakistan), Dr Hubert Krysztofiak (Poland), Dr Dan Valentin Anghelescu (Romania), Dr Goran Vasic (Serbia), Dr Roman Fano (Slovakia), Dr Vladimir Vachalik (Slovakia), Dr Matjaz Turel (Slovenia), Dr Inaki Arratibel (Spain), Dr Diego Garcia-German (Spain), Dr Lykke Tamm (Sweden), Dr German Clenin 
(Switzerland), Dr Stefan Froehlich (Switzerland), Dr Walter Frey (Switzerland), Dr Lukas Weisskopf (Switzerland), Dr Christian Schlegel (Switzerland), Dr Hanspeter Betschart (Switzerland), Dr Patrik Noack (Switzerland), Dr María Vittoria Comune (Thailand), Dr Michel Frenzel-Assih (Togo), Dr Tim Allardyce (Tonga), Dr Adem Cali (Turkey), Dr Igor Marunchak (Ukraine), Dr Bill Moreau (USA), Dr Dustin Nabhan (USA), Dr Kyle Wilkens (USA) and Dr David Weinstein (USA).

Contributors All authors contributed to the study conception and design, and data collection and interpretation. TS analysed the data and drafted the paper. All authors provided revisions and contributed to the final manuscript. TS is the guarantor.

Funding The IOC funded the data collection of the study.

Competing interests TS works as Scientific Manager in the Medical and Scientific Department of the IOC. LE is Head of Scientific Activities in the Medical and Scientific Department of the IOC, and Editor of the British Journal of Sports Medicine and Journal of Bone and Joint Surgery.

Patient consent for publication Not required.

Ethics approval The study was reviewed by the Medical Research Ethics Committee of the South-Eastern Norway Regional Health Authority (2011/388).

Provenance and peer review Not commissioned; externally peer reviewed.

Data availability statement All data relevant to the study are included in the article or uploaded as supplementary information.

\section{REFERENCES}

1. WHO. Global recommendations on physical activity for health. Geneva, Switzerland: WHO Press, 2010

2. CDC. Physical Activity and Health | The Benefits of Physical Activity $\mid C D C, 2018$. Available: https://www.cdc.gov/physicalactivity/basics/pa-health/index.htm [Accessed 21 Oct 2018].

3. Sarna S, Sahi T, Koskenvuo M, et al. Increased life expectancy of world class male athletes. Med Sci Sports Exerc 1993;25:237-44.

4. Kujala UMet al. Hospital care in later life among former world-class Finnish athletes. J Am Med Assoc 1996;276:216-20.

5. Teramoto M, Bungum TJ. Mortality and longevity of elite athletes. I Sci Med Sport 2010;13:410-6.

6. Clarke PM, Walter SJ, Hayen A, et al. Survival of the fittest: retrospective cohort study of the longevity of Olympic medallists in the modern era. Br J Sports Med 2015;49:898-902.

7. Zwiers R, Zantvoord FWA, Engelaer FM, et al. Mortality in former Olympic athletes: retrospective cohort analysis. BMJ 2012;345:e7456.

8. Drawer S, Fuller CW. Propensity for osteoarthritis and lower limb joint pain in retired professional soccer players. Br J Sports Med 2001;35:402-8.

9. Drawer S, Fuller CW. Evaluating the level of injury in English professional football using a risk based assessment process. Br J Sports Med 2002;36:446-51.

10. Lohmander LS, Östenberg A, Englund M, et al. High prevalence of knee osteoarthritis, pain, and functional limitations in female soccer players twelve years after anterior cruciate ligament injury. Arthritis Rheum 2004;50:3145-52.

11. von Porat $\mathrm{A}$, Roos EM, Roos H. High prevalence of osteoarthritis 14 years after an anterior cruciate ligament tear in male soccer players: a study of radiographic and patient relevant outcomes. Ann Rheum Dis 2004;63:269-73.

12. van Mechelen $W$, Hlobil H, Kemper HC. Incidence, severity, aetiology and prevention of sports injuries. A review of concepts. Sports Med 1992;14:82-99.

13. Finch C. A new framework for research leading to sports injury prevention. J Sci Med Sport 2006;9:3-9.

14. Bahr R, Reeser JC. Injuries among world-class professional beach volleyball players: the Fédération Internationale de Volleyball beach Volleyball injury study. Am I Sports Med 2003;31:119-25.

15. Junge A, Dvorak J, Graf-Baumann T, et al. Football injuries during FIFA tournaments and the Olympic games, 1998-2001: development and implementation of an injuryreporting system. Am J Sports Med 2004;32(1 Suppl):80S-9.

16. Taylor AE, Fuller CW, Molloy MG. Injury surveillance during the 2010 IRB women's rugby World Cup. Br J Sports Med 2011;45:1243-5.

17. Fuller CW, Laborde F, Leather RJ, et al. International rugby board rugby World Cup 2007 injury surveillance study. Br I Sports Med 2008;42:452-9.

18. Fuller CW, Taylor A, Raftery M. 2016 Rio Olympics: an epidemiological study of the men's and women's Rugby-7s tournaments. Br J Sports Med 2017;51:1272-8.

19. Hägglund $M$, Waldén $M, B a h r ~ R$, et al. Methods for epidemiological study of injuries to professional football players: developing the UEFA model. Br J Sports Med 2005;39:340-6.

20. Waldén $M$, Hägglund $M$, Ekstrand J. UEFA champions League study: a prospective study of injuries in professional football during the 2001-2002 season. Br J Sports Med 2005;39:542-6.

21. Waldén $M$, Hägglund $M$, Ekstrand J. Football injuries during European Championships 2004-2005. Knee Surg Sports Traumatol Arthr 2007;15:1155-62.

22. Ekstrand J, Hägglund $M$, Waldén $M$. Injury incidence and injury patterns in professional football: the UEFA injury study. Br I Sports Med 2011;45:553-8.
23. Hägglund $M$, Waldén $M$, Ekstrand J. UEFA injury study--an injury audit of European Championships 2006 to 2008. Br J Sports Med 2009;43:483-9.

24. Hägglund $M$, Waldén $M$, Magnusson $H$, et al. Injuries affect team performance negatively in professional football: an 11-year follow-up of the UEFA champions League injury study. Br J Sports Med 2013;47:738-42.

25. Webborn N, Willick S, Reeser JC. Injuries among disabled athletes during the 2002 winter Paralympic Games. Med Sci Sports Exerc 2006;38:811-5.

26. Junge A, Dvořák J. Football injuries during the 2014 FIFA World Cup. Br J Sports Med 2015;49:599-602.

27. Webborn N, Willick S, Emery CA. The injury experience at the 2010 winter Paralympic Games. Clin J Sport Med 2012;22:1-9.

28. Derman W, Schwellnus $M$, Jordaan E, et al. Illness and injury in athletes during the competition period at the London 2012 Paralympic games: development and implementation of a web-based surveillance system (WEB-IISS) for team medical staff. Br J Sports Med 2013:47:420-5.

29. Webborn N, Cushman D, Blauwet CA, et al. The Epidemiology of Injuries in Football at the London 2012 Paralympic Games. PM\&R 2016;8:545-52.

30. Schwellnus $\mathrm{M}$, Derman W, Jordaan E, et al. Factors associated with illness in athletes participating in the London 2012 Paralympic Games: a prospective cohort study involving 49910 athlete-days. Br J Sports Med 2013;47:433-40.

31. Derman W, Schwellnus MP, Jordaan E, et al. The incidence and patterns of illness at the Sochi 2014 winter Paralympic games: a prospective cohort study of 6564 athlete days. Br J Sports Med 2016;50:1064-8.

32. Derman W, Schwellnus MP, Jordaan E, et al. High incidence of injury at the Sochi 2014 winter Paralympic games: a prospective cohort study of 6564 athlete days. $\mathrm{Br}$ J Sports Med 2016;50:1069-74.

33. Derman $W$, Runciman $P$, Schwellnus $M$, et al. High precompetition injury rate dominates the injury profile at the Rio 2016 Summer Paralympic Games: a prospective cohort study of 51198 athlete days. Br I Sports Med 2018;52:24-31.

34. Derman W, Schwellnus MP, Jordaan E, et al. Sport, sex and age increase risk of illness at the RIO 2016 summer Paralympic games: a prospective cohort study of 51 198 athlete days. Br I Sports Med 2018;52:17-23.

35. Alonso J-M, Tscholl PM, Engebretsen $L$, et al. Occurrence of injuries and illnesses during the 2009 IAAF world athletics Championships. Br J Sports Med 2010:44:1100-5.

36. Alonso J-M, Edouard $\mathrm{P}$, Fischetto $\mathrm{G}$, et al. Determination of future prevention strategies in elite track and field: analysis of Daegu 2011 IAAF Championships injuries and illnesses surveillance. Br J Sports Med 2012;46:505-14.

37. Dvorak J, Junge A, Grimm K, et al. Medical report from the 2006 FIFA World Cup Germany. Br J Sports Med 2007;41:578-81.

38. Alonso J-M, Jacobsson J, Timpka T, et al. Preparticipation injury complaint is a risk factor for injury: a prospective study of the Moscow 2013 IAAF Championships. Br J Sports Med 2015;49:1118-24.

39. Feddermann-Demont $\mathrm{N}$, Junge $\mathrm{A}$, Edouard $\mathrm{P}$, et al. Injuries in 13 international athletics championships between 2007-2012. Br I Sports Med 2014;48:513-22.

40. Timpka T, Jacobsson J, Bargoria V, et al. Preparticipation predictors for Championship injury and illness: cohort study at the Beijing 2015 international Association of athletics Federations world Championships. Br J Sports Med 2017;51:271-6

41. Mountioy M, Junge A, Alonso JM, et al. Sports injuries and illnesses in the 2009 FINA world Championships (Aquatics). Br J Sports Med 2010;44:522-7.

42. Mountjoy M, Junge A, Benjamen S, et al. Competing with injuries: injuries prior to and during the 15th FINA world Championships 2013 (aquatics). Br J Sports Med 2015;49:37-43.

43. Prien A, Mountjoy M, Miller J, et al. Injury and illness in aquatic sport: how high is the risk? A comparison of results from three FINA world Championships. Br J Sports Med 2017:51:277-82

44. Torjussen J, Bahr R. Injuries among elite snowboarders (FIS Snowboard World Cup). Br J Sports Med 2006;40:230-4.

45. Flørenes TW, Bere T, Nordsletten L, et al. Injuries among male and female World Cup alpine skiers. Br J Sports Med 2009:43:973-8.

46. Flørenes TW, Heir S, Nordsletten L, et al. Injuries among World Cup freestyle skiers. Br J Sports Med 2010;44:803-8.

47. Flørenes TW, Nordsletten L, Heir S, et al. Recording injuries among World Cup skiers and snowboarders: a methodological study. Scand I Med Sci Sport 2011:21:196-205.

48. Junge A, Dvorak J. Injuries in female football players in top-level international tournaments. Br J Sports Med 2007:41(Supplement 1):i3-7.

49. Flørenes TW, Nordsletten L, Heir S, et al. Injuries among World Cup Ski and snowboard athletes. Scand J Med Sci Sports 2012;22:58-66.

50. Bakken A, Bere T, Bahr R, et al. Mechanisms of injuries in World Cup Snowboard cross: a systematic video analysis of 19 cases. Br I Sports Med 2011:45:1315-22.

51. Bere T, Flørenes TW, Nordsletten L, et al. Sex differences in the risk of injury in World Cup alpine skiers: a 6-year cohort study. Br I Sports Med 2014;48:36-40.

52. Major DH, Steenstrup SE, Bere T, et al. Injury rate and injury pattern among elite World Cup snowboarders: a 6-year cohort study. Br J Sports Med 2014;48:18-22.

53. Randjelovic S, Heir S, Nordsletten L, et al. Injury situations in Freestyle Ski cross (SX): a video analysis of 33 cases. Br J Sports Med 2014;48:29-35. 
54. Steenstrup SE, Bere T, Bahr R. Head injuries among Fis World Cup alpine and freestyle skiers and snowboarders: a 7-year cohort study. Br J Sports Med 2014; $48: 41-5$

55. Tuominen M, Stuart MJ, Aubry M, et al. Injuries in men's international ice hockey: a 7-year study of the International ice hockey Federation adult world Championship Tournaments and Olympic winter games. Br J Sports Med 2015;49:30-6.

56. Tuominen M, Stuart MJ, Aubry M, et al. Injuries in women's international ice hockey: an 8-year study of the world Championship tournaments and Olympic winter games. Br J Sports Med 2016;50:1406-12.

57. Tuominen M, Hänninen T, Parkkari J, et al. Concussion in the International ice hockey world Championships and Olympic winter games between 2006 and 2015. Br J Sports Med 2017;51:244-52.

58. Tuominen M, Stuart MJ, Aubry M, et al. Injuries in world junior ice hockey championships between 2006 and 2015. Br J Sports Med 2017;51:36-43.

59. Dvorak J, Junge A, Derman W, et al. Injuries and illnesses of football players during the 2010 FIFA World Cup. Br J Sports Med 2011;45:626-30.

60. Park KJ, Brian Byung S, Byung SB. Injuries in elite Korean fencers: an epidemiological study. Br J Sports Med 2017;51:220-5.

61. Lystad RP, Graham PL, Poulos RG. Exposure-adjusted incidence rates and severity of competition injuries in Australian amateur taekwondo athletes: a 2-year prospective study. Br J Sports Med 2013;47:441-6.

62. Bere T, Alonso J-M, Wangensteen A, et al. Injury and illness surveillance during the 24th men's Handball world Championship 2015 in Qatar. Br J Sports Med 2015;49:1151-6.

63. Loosemore M, Lightfoot J, Palmer-Green D, et al. Boxing injury epidemiology in the great Britain team: a 5-year surveillance study of medically diagnosed injury incidence and outcome. Br J Sports Med 2015;49:1100-7.

64. Siewe J, Rudat J, Zarghooni K, et al. Injuries in competitive boxing. A prospective study. Int J Sports Med 2015;36:249-53.

65. Westermann RW, Giblin M, Vaske A, et al. Evaluation of men's and women's gymnastics injuries: a 10-year observational study. Sports Health 2015;7:161-5.

66. Theilen T-M, Mueller-Eising W, Wefers Bettink P, Bettink PW, et al. Injury data of major international field hockey tournaments. Br J Sports Med 2016;50:657-60.

67. Kim K-S, Park KJ, Lee J, et al. Injuries in national Olympic level judo athletes: an epidemiological study. Br J Sports Med 2015;49:1144-50.

68. Brøgger-Jensen T, Hvass I, Bugge S. Injuries at the Bmx cycling European Championship, 1989. Br J Sports Med 1990;24:269-70.

69. Jayanthi NA, O'Boyle J, Durazo-Arvizu RA. Risk factors for medical withdrawals in United States tennis association junior national tennis Tournaments: a descriptive epidemiologic study. Sports Health 2009;1:231-5.

70. Lynall RC, Kerr ZY, Djoko A, et al. Epidemiology of national collegiate athletic association men's and women's tennis injuries, 2009/2010-2014/2015. Br J Sports Med 2016;50:1211-6.

71. Maquirriain J, Baglione R. Epidemiology of tennis injuries: an eight-year review of Davis cup retirements. Eur J Sport Sci 2016;16:266-70.

72. McCurdie I, Smith S, Bell PH, et al. Tennis injury data from the Championships, Wimbledon, from 2003 to 2012. Br J Sports Med 2017;51:607-11.

73. Pluim BM, Loeffen FGJ, Clarsen B, et al. A one-season prospective study of injuries and illness in elite junior tennis. Scand J Med Sci Sports 2016;26:564-71.

74. Pluim BM, Clarsen B, Verhagen $E$. Injury rates in recreational tennis players do not differ between different playing surfaces. Br J Sports Med 2018;52:611-5.

75. Best JP, Mclntosh A, Savage TN, et al. Injury surveillance project. Br J Sports Med 2003;2005:812-7.

76. Fuller CW, Taylor A, Molloy MG. Epidemiological study of injuries in international rugby Sevens. Clin J Sport Med 2010;20:179-84.

77. Junge A, Engebretsen L, Alonso JM, et al. Injury surveillance in multi-sport events: the International Olympic committee approach. Br J Sports Med 2008:42:413-21.

78. Junge A, Engebretsen L, Mountjoy ML, et al. Sports injuries during the summer Olympic Games 2008. Am J Sports Med 2009;37:2165-72.

79. Engebretsen L, Steffen K, Alonso JM, et al. Sports injuries and illnesses during the winter Olympic Games 2010. Br J Sports Med 2010;44:772-80.

80. Engebretsen L, Soligard T, Steffen K, et al. Sports injuries and illnesses during the London Summer Olympic Games 2012. Br J Sports Med 2013;47:407-14.

81. Soligard T, Steffen K, Palmer-Green D, et al. Sports injuries and illnesses in the Sochi 2014 Olympic winter games. Br J Sports Med 2015;49:441-7.

82. Soligard T, Steffen K, Palmer D, et al. Sports injury and illness incidence in the Rio de Janeiro 2016 Olympic summer games: a prospective study of 11274 athletes from 207 countries. Br J Sports Med 2017;51:1265-71.

83. Bahr R. No injuries, but plenty of pain? On the methodology for recording overuse symptoms in sports. Br J Sports Med 2009:43:966-72.

84. Clarsen B, Myklebust G, Bahr R. Development and validation of a new method for the registration of overuse injuries in sports injury epidemiology: the Oslo sports trauma research centre (OSTRC) overuse injury questionnaire. Br J Sports Med 2013:47:495-502.

85. Clarsen B, Rønsen O, Myklebust G, et al. The Oslo sports trauma research center questionnaire on health problems: a new approach to prospective monitoring of illness and injury in elite athletes. Br J Sports Med 2014;48:754-60.

86. Clarsen B, Bahr R. Matching the choice of injury/illness definition to study setting. purpose and design: one size does not fit all! Br J Sports Med 2014;48:510-2.

87. Mountjoy M, Junge $A$, Alonso JM, et al. Consensus statement on the methodology of injury and illness surveillance in FINA (aquatic sports): Table 1. Br J Sports Med 2016;50:590-6.

88. Russell K, Meeuwisse WH, Nettel-Aguirre A, et al. Injuries and terrain Park feature use among snowboarders in Alberta. Br J Sports Med 2011;45.

89. Russell K, Meeuwisse WH, Nettel-Aguirre A, et al. Feature-specific terrain park-injury rates and risk factors in snowboarders: a case-control study. Br J Sports Med 2014;48:23-8.

90. Stuart MJ, Smith A. Injuries in junior a ice hockey. A three-year prospective study. Am J Sports Med 1995;23:458-61.

91. Mölsä J, Airaksinen 0, Näsman 0, et al. Ice hockey injuries in Finland. Am J Sports Med 1997;25:495-9.

92. Pinto M, Kuhn JE, Greenfield ML, et al. Prospective analysis of ice hockey injuries at the junior a level over the course of one season. Clin J Sport Med 1999;9:70-4.

93. Benson BW, Meeuwisse WH, Rizos J, et al. A prospective study of concussions among national hockey League players during regular season games: the NHL-NHLPA concussion program. CMAJ 2011;183:905-11.

94. McKay CD, Tufts RJ, Shaffer B, et al. The epidemiology of professional ice hockey injuries: a prospective report of six NHL seasons. Br J Sports Med 2014;48:57-62.

95. Sell $K$, Hainline $B$, Yorio $M$, et al. Illness data from the US open tennis Championships from 1994 to 2009. Clin J Sport Med 2013;23:25-32.

96. Ruedl G, Schobersberger W, Pocecco E, et al. Sport injuries and illnesses during the first winter youth Olympic Games 2012 in Innsbruck, Austria. Br J Sports Med 2012;46:1030-7.

97. Schwellnus MP, Derman WE, Jordaan E, et al. Elite athletes travelling to international destinations $>5$ time zone differences from their home country have a 2-3-fold increased risk of illness. Br J Sports Med 2012;46:816-21.

98. Schwellnus M, Derman W, Page T, et al. Illness during the 2010 super 14 rugby union tournament - a prospective study involving 22676 player days. Br J Sports Med 2012;46:499-504.

99. Theron N, Schwellnus M, Derman W, et al. Illness and injuries in elite football players--a prospective cohort study during the FIFA Confederations Cup 2009. Clin J Sport Med 2013;23:379-83.

100. Al-Shaqsi S, Al-Kashmiri A, Al-Risi A, et al. Sports injuries and illnesses during the second Asian beach games. Br J Sports Med 2012;46:780-7.

101. Mäkelä MJ, Puhakka T, Ruuskanen 0 , et al. Viruses and bacteria in the etiology of the common cold. J Clin Microbiol 1998:36:539-42.

102. Spence L, Brown WJ, Pyne DB, et al. Incidence, etiology, and symptomatology of upper respiratory illness in elite athletes. Med Sci Sports Exerc 2007;39:577-86.

103. Schwellnus M, Soligard T, Alonso J-M, et al. How much is too much? (Part 2) International Olympic Committee consensus statement on load in sport and risk of illness. Br J Sports Med 2016;50:1043-52.

104. Walsh NP, Gleeson M, Shephard RJ, et al. Position statement. Part one: immune function and exercise. Exerc Immunol Rev 2011;17:6-63.

105. Gleeson M, Pyne DB. Respiratory inflammation and infections in high-performance athletes. Immunol Cell Biol 2016;94:124-31.

106. Svendsen IS, Taylor IM, Tønnessen E, et al. Training-related and competition-related risk factors for respiratory tract and gastrointestinal infections in elite cross-country skiers. Br J Sports Med 2016;50:809-15.

107. Walsh NP, Gleeson M, Pyne DB, et al. Position statement. Part two: maintaining immune health. Exerc Immunol Rev 2011;17:64-103 http://www.ncbi.nlm.nih.gov/ pubmed/21446353

108. Hanstad DV, Rønsen O, Andersen SS, et al. Fit for the fight? illnesses in the Norwegian team in the Vancouver Olympic Games. Br J Sports Med 2011;45:571-5.

109. Dijkstra HP, Pollock N, Chakraverty R, et al. Managing the health of the elite athlete: a new integrated performance health management and coaching model. Br J Sports Med 2014:48:523-31.

110. Fuller CW, Molloy MG, Bagate $C$, et al. Consensus statement on injury definitions and data collection procedures for studies of injuries in rugby union. Clinical Journal of Sport Medicine 2007; 17:177-81.

111. Bahr R, Holme I. Risk factors for sports injuries -- a methodological approach. $\mathrm{Br} J$ Sports Med 2003;37:384-92.

112. Inklaar H. Soccer injuries. I: incidence and severity. Sport Med 1994;18:55-73.

113. Finch CF. An overview of some definitional issues for sports injury surveillance. Sports Med 1997:24:157-63. 